\title{
JUSTIÇA E DEMOCRACIA
}

\section{A mulher no mercado de trabalho uberizado em tempos de pandemia: breve análise sobre os caminhos da desigualdade de gênero laborativo no Brasil}

Women in the uploaded labor market in pandemic times: a brief analysis on the paths of laborative gender inequality in Brazil

Catrine Cadja Indio do Brasil da Mata, M.Sc.

Mestra em Economia Regional e Políticas Públicas - UESC, Professora de Direito, AGES. https://orcid.org/0000-0003-1432-6338

Miquéias Moreira de Araújo

Mestrando em Educação e Diversidade - UNEB.

Discente do curso de Direito, AGES. https://orcid.org/0000-0002-6584-2175

João Kleber Ferreira de Melo

Discente do curso de Direito, AGES. https://orcid.org/0000-0001-6447-0464

Leonilson Alves Araújo de Souza

Discente do curso de Direito, AGES. https://orcid.org/0000-0002-7273-8050

Antônio Igor Gama da Silva

Discente do curso de Direito, AGES. https://orcid.org/0000-0001-9333-4226

Jackson Ramos da Cruz

Discente do curso de Direito, AGES. https://orcid.org/0000-0003-4884-1469

\section{Luana Rodrigues Soares}

Discente do curso de Direito, AGES. https://orcid.org/0000-0002-5993-601X 
Neuraci Silva Guimarães

\title{
Discente do curso de Direito, AGES. https://orcid.org/0000-0003-0230-0376 \\ Valdênia da Glória Máximo Azevedo
}

Discente do curso de Direito, AGES. https://orcid.org/0000-0003-3419-0394

\section{Luiz Justiniano dos Santos}

Discente do curso de Direito, AGES. https://orcid.org/0000-0003-4757-0011

RESUMO: Este estudo visou analisar os problemas decorrentes da uberização do trabalho a partir da cultura digital, focalizado em compreender como as mulheres se situam neste contexto. A partir desta compreensão, visou-se encontrar um paralelo entre a inserção das mulheres no crescente trabalho informal e a crise do trabalho provocada pela pandemia da COVID-19. O artigo se desenvolve a partir de uma construção da análise histórica, utilizando metodologicamente a pesquisa documental e revisão bibliográfica sob a ótica do papel da mulher nos espaços formais/informais de trabalho, ante ao crescimento e tomadas de espaços de trabalho que pertenciam apenas à figura masculina. É nesse contexto que se discute a uberização do trabalho e suas implicações na vida laboral feminina, frente a ausência de direitos e garantias trabalhistas que podem culminar em um maior acirramento da desigualdade de gênero no país.

Palavras-chave: trabalho feminino; desigualdade salarial; COVID-19; home office.

\begin{abstract}
This repair study analyzed the problems that arise in new contexts arising from digital culture and the uberization of work, thematically focusing on understanding how women are placed in this context and from this understanding find a parallel between the growing demand for informal work and the crisis of the labor market. caused by the COVID-19 pandemic. The article is appropriated from a construction of historical analysis, using methodologically a documentary research and bibliographic review from the perspective of the role of women in formal / informal workspaces, in view of the growth and work space that belonged only to the male figure. It is in this context that the uberization of work and its possibility in female working life is discussed, given the absence of labor rights and guarantees that can culminate in a greater worsening of gender inequality in the country.
\end{abstract}

Keywords: women's work; wage inequality; COVID-19; home office.

Laborare. Ano IV, Número 7, Jul-Dez/2021, pp. 30-47. ISSN 2595-847X. https://revistalaborare.org/ DOI: https://doi.org/10.33637/2595-847x.2021-91 


\section{INTRODUÇÃO}

Sabe-se que a cultura digital mudou a forma como olhamos o mundo influenciando novos mecanismos para organização do trabalho, a partir das interferências das plataformas digitais no cotidiano das pessoas e seus impactos no mundo contemporâneo (ABILIO, 2019). Uma vez que a partir da cultura digital no contexto global se estabelecem diferentes tipos de relações trabalhistas, surge a uberização do trabalho que pode ser conceituada como um "novo estágio da exploração do trabalho, que traz mudanças qualitativas ao estatuto do trabalhador, à configuração das empresas, assim como às formas de controle, gerenciamento e expropriação do trabalho (ABÍLIO, 2019, p.2).

Deste modo, esse trabalho traz reflexões e provocações a partir dessa nova forma de organização do trabalho no Brasil, uma vez que se percebe que com a escassez do trabalho formal, cada vez mais o trabalho informal uberizado torna-se visível ocupando espaços importantes para a classe trabalhadora.

Este estudo visa ainda analisar os personagens femininos e os processos em que estão inseridas no mundo do trabalho, norteado por questões como: quais as consequências da uberização para o trabalho da mulher e qual a sua relação com o ambiente familiar e o próprio mercado de trabalho. A partir dessas questões, a pesquisa busca compreender como ocorrem as mudanças no contexto do trabalho, sendo ponto de partida para se perceber onde a mulher se enquadra neste contingente e quais dificuldades têm enfrentado para sua inserção.

Ao mencionar a inserção da mulher no mercado de trabalho, faz-se necessário uma reflexão na história da luta feminina ao longo do tempo, a iniciar pelo surgimento das indústrias, onde as mulheres foram chamadas para trabalhar, porém, recebendo salários mais baixos que os homens e, por isso, até priorizadas para as atividades do setor (BAYLÃO; SCHETTINO, 2014). Deste modo, apesar do aspecto positivo dos empregos em indústrias para a inserção da mulher no mercado, foram eles também que fomentaram a diferença de salários entre os gêneros. Contudo, em 1970, graças aos movimentos feministas que tomaram conta dos Estados Unidos da América (EUA), o que acabou por refletir diretamente no Brasil, as mulheres começaram a exercer, também, outras funções na sociedade: atendentes, costureiras, professoras, entre outras, o que culminou por aumentar a participação da mulher no mercado de trabalho, mesmo que a passos lentos (BRUSCHINI; LOMBARDI, 2011).

Laborare. Ano IV, Número 7, Jul-Dez/2021, pp. 30-47. ISSN 2595-847X. https://revistalaborare.org/ DOI: https://doi.org/10.33637/2595-847x.2021-91 
Mesmo com o avanço dessas conquistas, grande parte das mulheres ainda continua desenvolvendo o trabalho doméstico concomitantemente ao trabalho remunerado. No entanto, as mulheres têm ganhado voz no mercado de trabalho. Uma prova disto são os princípios de empoderamento elaborado pela Organização das Nações Unidas para a Igualdade de Gênero e o Empoderamento das Mulheres (ONU Mulheres) e o Pacto Global, com um conjunto de considerações para fomentar oportunidades oferecidas por grandes empresas e companhias para o público feminino, ajudando empresas a incorporarem em seus negócios práticas que promovam a equidade de gênero e o empoderamento das mulheres.

Além da desigualdade de salários e uma gama de problemas relacionados à discriminação de gênero no mercado de trabalho, a questão social referente ao trabalho informal e uberização vem trazer novos problemas que dificultam a inserção das mulheres no mercado formal de trabalho, lançando-as no mercado informal precarizado.

Neste contexto, é importante considerar que a pandemia da doença do coronavírus (COVID-19) intensifica a precarização das relações de trabalho, ao mesmo tempo em que desvela algumas de suas ideologias. Se os dados do mercado de trabalho e a regulamentação de algumas atividades já mostravam um cenário desfavorável à classe trabalhadora no período imediatamente anterior aos primeiros casos de COVID-19 no Brasil, as medidas de isolamento social, associadas a medidas, no mínimo, tímidas do Estado para compensar o afastamento dos trabalhadores de suas atividades laborais exacerbam o risco, a insegurança e o desemprego, sendo agravadas pelas recentes retiradas de proteções sociais da população.

Deste modo, a partir da pesquisa bibliográfica e revisão de literatura adotadas como metodologia neste trabalho, infere-se que a pandemia da COVID-19 vem dando espaço cada vez mais ao que se chama de trabalho uberizado, incluindo o trabalho feminino como um importante força produtiva para o crescimento deste fenômeno laborativo.

\section{DA MODERNIDADE À CONTEMPORANEIDADE: O QUE MUDOU PARA AS MULHERES NO AMBIENTE DE TRABALHO? UMA BREVE ANÁLISE}

O trabalho braçal foi considerado por muito tempo como único tipo de trabalho e sempre foi relacionado com a figura masculina, isto é, desde os primórdios da humanidade a obrigação de trabalhar era conferida aos homens. Às mulheres relegava-se as obrigações de permanecerem em casa cuidando dos lares e dos filhos (OST, 2009).

Laborare. Ano IV, Número 7, Jul-Dez/2021, pp. 30-47. ISSN 2595-847X. https://revistalaborare.org/ DOl: https://doi.org/10.33637/2595-847x.2021-91 
É perceptível que o ambiente de trabalho sempre foi machista. Ocorre, que com o passar dos anos, o contexto vem sendo modificado e as mulheres começaram a lograr vagas em postos de trabalhos, especialmente nas fábricas surgidas durante a revolução industrial, uma vez que após esse grande marco da humanidade exsurge a necessidade de contratar mais mão de obra para suprir a necessidade financeira do sistema capitalista (OST, 2009). Portanto, as mulheres que antes se limitavam ao trabalho doméstico, têm, agora, oportunidades de ingressar no mundo do trabalho outrora exclusivamente pertencente à figura masculina. Neste sentido, explana Stelamaris Ost (2009):

Nessa época, o trabalho da mulher foi muito utilizado, principalmente na operação das máquinas. Os empresários preferiam as mulheres nas indústrias porque elas aceitavam salários inferiores aos dos homens, porém faziam os mesmos serviços que estes. Em razão disso, as mulheres sujeitam-se a jornadas de trabalho de 14 a 16 horas por dia, salários baixos, trabalhando muitas vezes em condições prejudiciais à saúde e cumprindo obrigações além das que lhes eram possíveis, só para não perder o emprego.

Entretanto, sabe-se que mesmo após o surgimento de oportunidades o trabalho nunca deixou de ser desigual, tanto é assim que o gênero feminino mesmo exercendo cargos idênticos ou semelhantes aos do sexo masculino, continuava a receber uma contraprestação salarial muito menor que a remuneração pela prestação de serviço masculino (ARAÚJO; LOMBARDI, 2013)

Outro aspecto de suma importância é que as mulheres, muitas das vezes, exercem duplas jornadas, pois além de irem aos postos de trabalhos prestarem seus serviços, se veem obrigadas a cumprir com as tarefas de casa (FRANÇA; SCHIMANSKI; 2009). As mulheres, portanto, se veem mais longe de momentos de lazer em virtude de outras tarefas (GARCIA, 2009).

Neste sentido, é pertinente citar a evolução econômica pela qual passou o Brasil na primeira década do século XXI, ao passo que segundo dados do Instituto Brasileiro de Geografia e Estatística (IBGE) trazidos por Araújo e Lombardi (2013, p. 461), no Brasil houve um crescimento entre 2011 a 2009 de $22,8 \%$ de ocupação dos postos de trabalhos, enquanto o sexo masculino teve um crescimento de $18,9 \%$ naquele período. Apesar do crescimento importante das mulheres no mercado, dez anos depois, o IBGE divulgou em 2019 que $54,5 \%$ das mulheres com 15 anos ou mais integra a força de trabalho no país, enquanto entre os homens esse percentual chega a $73,7 \%$.

Laborare. Ano IV, Número 7, Jul-Dez/2021, pp. 30-47. ISSN 2595-847X. https://revistalaborare.org/ DOl: https://doi.org/10.33637/2595-847x.2021-91 
O crescimento das mulheres nos postos de trabalho é um fator importante, porém a realidade é que ainda há muito a ser conquistado, especialmente no que diz respeito a igualdade salarial, uma vez que segundo os dados divulgados pelo IBGE através da Pesquisa Nacional por Amostra de Domicílios (PNAD) em 2019 mostrou que a desigualdade salarial entre homem e mulher ainda é relativamente alta, apontando que naquele ano, a renda média das mulheres foi de $\mathrm{R} \$ 1.985,00$, enquanto a dos homens foi de R $\$ 2.555,00$. Neste mesmo sentido, o Departamento Intersindical de Estatística e Estudos Socioeconômicos (DIEESE, 2020) divulgou que mulheres ganharam $22 \%$ a menos do que os homens em 2019, aumentando essa diferença para $38 \%$ quando se compara aos trabalhadores com ensino superior.

No Brasil esse tema tem sido aprofundado, sobretudo no que diz respeito a como as relações desiguais na sociedade e no trabalho impactam em diversas formas de violência de gênero - ou seja, a violência sofrida pelo simples fato de ser mulher. Conforme o estudo realizado pelo Instituto de Pesquisa Econômica Aplicada (IPEA) em 2020, as medidas tomadas para a contenção da COVID-19, como a suspensão de aulas e a exigência de que famílias fiquem em casa, resultaram em maior sobrecarga de trabalho para mulheres e no aumento da violência que sofrem.

No momento em que vários profissionais passaram a trabalhar no regime de homeoffice, por conta da pandemia da COVID-19, houve também a necessidade de equilibrar o trabalho remunerado com tarefas domésticas. Porém esse fenômeno não atinge as pessoas de forma igual, tendo em vista que para mulheres, essa realidade foi mais sentida.

Um estudo realizado pelo IPEA, em 2019, discute os efeitos da participação da mulher no mercado de trabalho, que relata a violência doméstica e familiar contra as mulheres, especialmente a violência cometida pelo homem com quem mantém vínculo afetivo ou já manteve. A pesquisa demonstra que o índice de violência contra as mulheres que integram a população economicamente ativa, ou seja, que estão inseridas em atividades de trabalho $(52,2 \%)$ é quase duas vezes maior do que a taxa de violência doméstica entre aquelas que não estão no mercado de trabalho (de $24,9 \%$ ). O mesmo estudo concluiu que mulheres que trabalham fora e coabitam com o parceiro têm menor probabilidade de sofrer violência do que as que estão empregadas e separadas do agressor.

Chamam atenção os movimentos de defesa de direitos da mulher mostrando que empoderar economicamente as mulheres é suficiente para que elas saiam de uma situação de violência. A dependência econômica é vista como um fator central para que

Laborare. Ano IV, Número 7, Jul-Dez/2021, pp. 30-47. ISSN 2595-847X. https://revistalaborare.org/ DOI: https://doi.org/10.33637/2595-847x.2021-91 
mulheres permaneçam em uma relação conjugal violenta, mas é preciso considerar outros fatores quando se fala em enfrentar a violência doméstica e familiar.

O estudo realizado, citado acima, revela ainda que, em alguns casos, o empoderamento econômico pode contribuir para o efeito contrário, fazendo com que elas sofram mais violência. Através do estudo, fica evidente que a violência sofrida deve ser atribuída não ao fato de a mulher trabalhar fora, mas à cadeia de poder e dominação com a qual ela está rompendo ao entrar no mercado de trabalho e garantir independência econômica. Ao apontar dados do IBGE, o estudo em comento demonstra que cerca de 6 milhões de mulheres (60\% delas, negras), ou 14\% daquelas que estão na força de trabalho, são empregadas domésticas. Os dados demonstram, ainda, que $9 \%$ das mulheres empregadas domésticas do mundo estão no Brasil.

A Constituição da República Federativa do Brasil (CRFB), de 1988, reconhece o valor social do trabalho, como fonte de realização pessoal, promoção do bem comum e da dignidade humana, para efetivação de uma vida plena. Para tanto, prevê a garantia de igualdade de gênero na relação de trabalho, proibindo diferença de remuneração justa entre homens e mulheres, promovendo melhores condições de trabalho a todos e a todas, bem como o desempenho de um trabalho saudável, livre e protegido.

De acordo com o princípio fundamental da isonomia, homens e mulheres são iguais em direitos e obrigações, nos termos do art. $5^{\circ}$, inciso I, da CRFB. De outro lado, no rol dos direitos sociais trabalhistas, $\mathrm{o}$ art. $7^{\circ}$ da mesma Carta estabelece a proteção do mercado de trabalho da mulher.

A Consolidação das Leis do Trabalho (CLT), por sua vez, assegura à mulher a igualdade de oportunidades ao ingressar no mercado de trabalho, por meio de vedações impostas ao empregador. A CLT visa assegurar o livre e permanente acesso da mulher ao mercado de trabalho, entre outras disposições, estabelecendo normas de proteção ao trabalho feminino, conforme seus artigos 372 a 401, as quais dispõem sobre a duração e as condições do trabalho da mulher, a discriminação contra a mulher, o trabalho noturno, os períodos de descanso, os métodos e locais de trabalho e a proteção ao matrimônio e à maternidade, sendo este último assunto de grande importância e relevância na vida da mulher trabalhadora.

Vislumbra-se da própria leitura da CLT em seu art. 337, a possibilidade de adoção de medidas com o objetivo de proteger o mercado de trabalho das mulheres, afastando de forma expressa a possibilidade de reduzir o salário.

Laborare. Ano IV, Número 7, Jul-Dez/2021, pp. 30-47. ISSN 2595-847X. https://revistalaborare.org/ DOI: https://doi.org/10.33637/2595-847x.2021-91 
É de todo oportuno frisar que o art. $9^{\circ}, \S 2^{\circ}$, II, da Lei. n. ${ }^{\circ} 11.340 / 2006$, conhecida como Lei Maria da Penha, estabelece que deve ser assegurado à mulher vítima de violência doméstica e familiar o afastamento do emprego, com a finalidade de preservar sua integridade física e psicológica, com a manutenção do vínculo trabalhista, pelo período de até seis meses.

Conforme a lei supracitada, caso o agressor não esteja importunando a vítima, bem como no caso de cumprimento correto das medidas protetivas estabelecidas ou na hipótese de ser preso em flagrante, a concessão do afastamento do emprego não se justifica, porquanto a empregada não corre riscos consideráveis. A previsão de tal medida mostra-se necessária e de extrema importância, pois assegura a preservação física e psicológica da mulher, tal como garantir sua afirmação, inclusive profissional, perante a sociedade.

O direito de manutenção do vínculo trabalhista da empregada vitimada pela violência doméstica tem sido considerado uma nova modalidade de garantia de emprego, aliás é uma evidente constatação de defesa ao princípio da continuidade da relação empregatícia (LEITE, 2020).

No caso específico da Lei Maria da Penha, a norma tem a finalidade de preservar o contrato de trabalho exclusivamente durante o período de seis meses, enquanto a empregada encontrar-se afastada das suas atividades laborais, e não visa à tutela do emprego após o retorno da obreira às suas atividades normais no local de trabalho (MARTINS, 2012).

Ademais, a disposição legal que garante a manutenção do contrato de trabalho, somada ao princípio da continuidade da relação de emprego, visa proteger o vínculo empregatício celebrado e deixa claro que haverá a garantia somente enquanto a medida estiver sendo aplicada. Em atenção ao princípio da legalidade, a lei é omissa quanto à tutela do emprego após o encerramento do prazo de seis meses.

Sendo assim, conforme preconiza a legislação vigente, a empregada terá direito à garantia de emprego durante o período de afastamento permitido pela lei, dentro do qual, caso seja dispensada, terá direito à reintegração. Por outro lado, ultrapassado esse prazo, o empregador reassume com plenitude o seu poder diretivo, podendo rescindir o contrato, com o pagamento das verbas rescisórias devidas.

É notório que dos primeiros dias da humanidade, perpassando pela idade média, até os dias de hoje as mulheres vêm realizando tarefas importantes no que diz respeito a

Laborare. Ano IV, Número 7, Jul-Dez/2021, pp. 30-47. ISSN 2595-847X. https://revistalaborare.org/ DOI: https://doi.org/10.33637/2595-847x.2021-91 
conquista dos seus direitos, cada vez mais o gênero feminino está se inserindo no mercado de trabalho, contudo, há muito o que ser alcançado, especialmente no que diz respeito a igualdade entre os sexos, uma vez que, embora garantido constitucionalmente, como também, através da CLT, percebe-se uma clara violação do princípio da isonomia na relação de trabalho, sobretudo, em relação ao salário. É evidente a desigualdade entre homens e mulheres.

\section{A UBERIZAÇÃO DO TRABALHO É PIOR PARA ELAS: A PANDEMIA, O TRABALHO, A CASA, A FAMÍLIA E A SOBRECARGA DAS MULHERES}

O cenário contemporâneo trabalhista no Brasil se desenvolveu principalmente a partir da reforma ocorrida na CLT em 2017, que, aliada aos processos de terceirização, contribuíram para o aprimoramento desse modelo de gestão, causando aumento no número de desempregados, bem como o crescimento do número de trabalhadores informais em todo o país de acordo com Biavaschi (2014). Além disso, diante do cenário político conturbado dos últimos anos, o emprego informal vem ganhando muito espaço, proporcionando às pessoas uma lógica pessimista, que embora o oferecendo novas formas de trabalhar e uma garantia de mensalidade renda, gera insegurança.

Em 2014 com a chegada da empresa Uber no Brasil, surgiu um novo modelo de trabalho, com um modelo mais informal e flexível. Logo em seguida, surgiram outras empresas com as mesmas características, como: Cabify, 99 Táxi, Loggi, iFood e Rappi. Segundo o IBGE, até o fim de 2019 número de motoristas de aplicativo teve um aumento significativo nos últimos anos, saltando para mais de um milhão de usuários cadastrados.

Com o surgimento desse fenômeno social, surge o termo uberização, que retrata o amplo processo de informalização do trabalho, processo que trouxe consigo diversas mudanças valorativas que mudaram o conceito do trabalho informal. Essas mudanças podem ser entendidas como mais um avanço no processo de transigência e flexibilização do trabalho. A essa cultura soma-se a cultura empresarialempreendedora, que incorpora a ideologia da liberdade possibilitada pela internet (ABÍLIO, 2017) operando também, com um novo meio de monopolização de atividades econômicas (SLEE, 2017) e de centralização do controle sobre o trabalho.

A Uber e as outras plataformas que prestam serviços digitais estão ganhando mais notoriedade por serem as propagadoras dessas novas formas de trabalho, e a essência central dessas plataformas é a de proporcionar às pessoas algo que, até então, era fora do comum, que é o poder de dispensar algum serviço, pois sabe que não existem

Laborare. Ano IV, Número 7, Jul-Dez/2021, pp. 30-47. ISSN 2595-847X. https://revistalaborare.org/ DOI: https://doi.org/10.33637/2595-847x.2021-91 
"amarras" trabalhistas que exerçam controle sobre ele. Embora essa possibilidade fosse perceptível nas cadeias produtivas mundiais e suas enormes redes de subcontratação (KLEIN, 2002). Desse modo, esse processo transforma o trabalhador em seu "auto gerente" e acarreta em um acúmulo de pessoas subordinadas a uma única empresa.

Em meio ao caos da saúde pública mundial, especialistas sugerem, que, para conter o avanço do novo coronavírus, Covid-19, o distanciamento social seja um dos meios mais eficazes, visto que, segundo Souza (2020, p. 2):

"permite reduzir a transmissão de doenças cujo contágio se dá pela proximidade física das pessoas".

Nesse contexto, o setor informal de trabalho aumentou consideravelmente, visto à crescente no desemprego mundial global, posto que conforme Costa (2020, p.4):

"além da crise sanitária, uma das consequências da pandemia é o aumento do desemprego e, portanto, a elevação da informalização do trabalho, dos terceirizados, dos subcontratados, dos flexibilizados, dos trabalhadores em tempo parcial e do subproletariado".

Durante a pandemia de COVID-19, o país perdeu 716 mil empresas. É o que mostra pesquisa inédita do IBGE sobre o impacto da crise do novo coronavírus nas companhias divulgada na quinta-feira. $\mathrm{O}$ número representa mais da metade de 1,3 milhão de firmas que estavam com atividades paralisadas temporária ou definitivamente na primeira quinzena de junho, devido às medidas de distanciamento social, segundo matéria de O GLOBO (CAPETTI, 2020).

Além disso, investigação realizada por pesquisadores do Instituto de Economia da Universidade Federal do Rio de Janeiro (IE/UFRJ) em parceria com o Institut de Recherche pour le Développement (IRD, França) observa-se forte correlação entre a proporção de trabalhadores informais de um determinado município, o número de casos positivos e o de óbitos (ROUBAUD et al., 2020). Analisando os dados disponíveis para as 5.570 cidades brasileiras, o modelo econômico estimou que cada 10 pontos percentuais a mais na proporção de informais está associado a um aumento de $29 \%$ na taxa de contágio e $38 \%$ na taxa de mortalidade pela COVID- 19 . (CARDOSO; PERES, 2020).

Com o índice desenfreado de desemprego a taxa de informalidade cresce assustadoramente, dando espaço para o que chamamos hoje em dia de uberização do

Laborare. Ano IV, Número 7, Jul-Dez/2021, pp. 30-47. ISSN 2595-847X. https://revistalaborare.org/ DOI: https://doi.org/10.33637/2595-847x.2021-91 
trabalho, que, apontado por Abílio (2019) como uma tendência desse reorganizar o trabalho a partir de novas formas de controle, gerenciamento e subordinação.

A crescente da chamada uberização do contrato de trabalho em tempos de pandemia desponta para questionamentos sobre as condições laborais das pessoas que fazem entregas por aplicativos, uma vez que de acordo com pesquisa apontada pela BBC News (2020):

Os dados indicam remuneração menor, jornadas longas e a migração de profissionais qualificados de outras áreas durante a pandemia, em meio ao alto risco de contágio pela COVID-19 que os trabalhadores enfrentam durante as entregas.

Enquanto as medidas de restrição aumentam e, aqueles que têm o privilégio de manter-se em casa, sabendo que não perderão seus empregos, as cumprem. Porém os trabalhadores informais vão às ruas para garantir que o básico chegue até essas famílias, assim, segundo Cerioni (2020):

Ao mesmo tempo surge uma preocupação enorme sobre a proteção social desses trabalhadores uma vez que o crescimento da demanda por entrega criou uma preocupação sobre a exposição desses trabalhadores em um período de pandemia.

Dito isso, resta claro que, quem os maiores prejudicados são os próprios trabalhadores informais, pois desamparados legalmente, diferentemente dos funcionários que estão trabalhando na modalidade home-office pois não se distingue entre o trabalho realizado no estabelecimento do empregador, o executado no domicílio do empregado e o realizado a distância, desde que estejam caracterizados os pressupostos da relação de emprego (CASTILHO, 2019).

Sendo assim, e conforme afirma, Moreira e Hermanson (2019), a uberização pode ser considerada como uma face moderna das terceirizações, uma vez que as empresasaplicativas têm alta visibilidade, contudo, pouca materialidade, apresentando-se apenas como mediadoras entre o trabalhador e o consumidor.

Nessa mesma lógica a crescente transformação do mercado de trabalho e o incremento das novas tecnologias, antenadas com a cultura digital, mudaram drasticamente a maneira como se relacionavam empresas e empregados. Com a uberização, direitos trabalhistas conquistados ao longo de processos históricos vêm sendo esquecidos sob argumento da autonomia que existe neste tipo de relação contratual. Apesar das mudanças trazidas pela tecnologia, a desigualdade existente

Laborare. Ano IV, Número 7, Jul-Dez/2021, pp. 30-47. ISSN 2595-847X. https://revistalaborare.org/ DOI: https://doi.org/10.33637/2595-847x.2021-91 
entre homens e mulheres tanto em relação a diferença salarial quanto ao cumprimento da jornada de trabalho, permanece.

No Brasil, como forma de mascarar a precariedade do trabalho, as empresas denominaram de colaboradores ou parceiros aqueles que se vinculam a elas, fazendo acreditar que com essa autonomia, além de parceiros seriam também patrões. Justamente por terem aceito por "livre e espontânea vontade" firmar uma prestação de serviço que exige muitas vezes o uso do transporte particular, valores fixos de remuneração e com alta jornada diária, tendo a ilusão de donos dos próprios negócios. Tudo isso sem nenhuma proteção legal. Dessa maneira, as empresas se eximem de qualquer obrigação legal no âmbito trabalhista - (férias, $13^{\circ}$ salário, seguro desemprego, etc. - , pois a mera prestação de serviços não configura emprego formal (CAMINHA, 2019).

O mercado global conta atualmente com os mais diversos tipos de aplicativos (APPS) que prestam serviços dos mais variados, tal como: Uber (transporte de passageiros), Ifood (entrega à domicilio de comidas), Airbnb (aluguel de residências, apartamentos por temporada), essas empresas atraem mão de obra menos qualificada, geralmente "autônomos" para fazerem parte do grupo. Porém, não dá ao prestador de serviço nenhuma segurança jurídica em relação às atividades realizadas.

Um modelo de empresa que trabalha de modo semelhante é a Natura, maior empresa brasileira de cosméticos que se utiliza de revendedores/as nos mais diversos lugares do país, que com seus próprios recursos fazem visitas, amostragem de catálogos, solicitam mercadorias e ainda entregam os pedidos nas casas de seus clientes, sem a empresa se responsabilizar por nenhum custo ou risco advindo dessa relação, ou seja, diminui o número de trabalhadores vinculados a empresa e aumenta sua lucratividade (COSTHEK, 2013).

Com a pandemia nota-se haver um aumento na desigualdade de gêneros no mercado de trabalho, além das demissões em massa de trabalhadores, em sua maioria mulheres (DOLCE, 2019). As medidas de distanciamento social impostas pelo Estado para frear a disseminação do Coronavírus fizeram com que milhares de crianças deixassem de frequentar o ambiente escolar, e consequentemente permanecem mais em suas casas, por conta disso, o estudo está sendo feito remotamente por grande parte das instituições de ensino.

Dessa forma, temos visto milhares de trabalhadoras abandonando seus empregos para dar atenção aos afazeres do lar e aos cuidados dos seus filhos, aumentando o déficit de mulheres no mercado de trabalho. Essa triste realidade mostra que a sociedade

Laborare. Ano IV, Número 7, Jul-Dez/2021, pp. 30-47. ISSN 2595-847X. https://revistalaborare.org/ DOI: https://doi.org/10.33637/2595-847x.2021-91 
ainda patriarcal, sujeita sempre as mulheres a responsabilidade pela execução das tarefas domésticas em detrimento do seu trabalho assalariado, já impactado pela diferença do valor pago aos trabalhadores do sexo masculino.

O dilema da necessidade de auferir renda, por si só, abarca grandes questionamentos e dúvidas para um futuro próximo, que tradicionalmente confere segurança social ao ente que trabalha, e consequentemente amparado legal pelo Instituto Nacional de Seguridade Social (INSS). Nas novas relações de trabalho, o poderio de fazer o trabalho de forma individual está iminente, conforme coaduna Standing (2011), porém, apegar-se a ideia de que isso seria suficientemente satisfatório e traria inúmeros benefícios aos trabalhadores, ou meramente só eles, é uma ilusão.

Para Scholz (2017), os riscos de desemprego trazem danos à saúde, como doenças crônicas, gastos de custo não contabilizados, e até mesmo à vida, em assaltos, sequestros, e acidentes de trânsito mostram-se existentes. O IBGE (2016), aponta que nas relações de empregado e empregador, em que a figura da mulher se encontra claramente desvalorizada tão somente pelo quesito de gênero, também persiste na nova modalidade de uberização. Além de todas as questões impostas, as mulheres ainda lidam, constantemente, com questionamentos pessoais sobre se irão dar conta, se não é perigoso, se o companheiro/a aprova, ou até mesmo se não tem medo desse tipo de trabalho.

Estudos realizados pelo IBGE (2016) apontam que as mulheres trabalhavam 73\% horas a mais que os homens, e em alguns Estados do Nordeste, potencializando as questões culturais, ultrapassando esse número em mais de $80 \%$ dos casos. Importante deixarmos explícito que nesta amostra são incluídas tanto mulheres casadas quanto solteiras. Para Giorgi (2019), esses aspectos integram o conceito de uma desigualdade transversal, pois não importam quais as legislações criadas ou os aspectos de trabalho, existirá a mesma aplicação e desproporção de salário e condições para a figura feminina no campo de trabalho.

Em recente campanha da Uber, em 2018, visivelmente ilustrada em seu site, eles publicaram em diversos meios midiáticos e campanhas de divulgação e impulso, sobre o compromisso assumido com as brasileiras, elencando os requisitos que, caracterizados por eles, trazem uma maior segurança aos motoristas e compartilhando através de cartilhas educativas sobre a existência de desigualdade de gênero presente em nossa realidade, como também botão de segurança, facilmente acionado e interligado com o sistema policial, sinal de GPS ${ }^{1}$ a um toque, levando a localização atual para pessoas de sua confiança anteriormente pré-selecionadas em parceria com

$1 \mathrm{GPS}=$ Global Positioning System ou Sistema de posicionamento global

Laborare. Ano IV, Número 7, Jul-Dez/2021, pp. 30-47. ISSN 2595-847X. https://revistalaborare.org/ DOI: https://doi.org/10.33637/2595-847x.2021-91 
a iniciativa privada, construída através de programa que visa trazer um amparo social para mulheres vítimas dessa insegurança.

No Brasil com a realidade de violência contra as mulheres e desigualdade de gênero no mercado de trabalho, são necessárias ações mais efetivas para solucionar as questões determinantes dos problemas advindos com as relações de trabalho surgidas a partir da uberização, articulando as necessidades pessoais e individuais com as disposições de igualdade necessárias para valorização da classe trabalhadora feminina.

\section{CONSIDERAÇÕES FINAIS}

O mercado global conta atualmente com os mais diversos tipos de aplicações que prestam os mais diversos serviços como: Uber (transporte de passageiros), Ifood (entrega ao domicílio), Airbnb (aluguer de casas, apartamentos por temporada), e para o funcionamento dessa engrenagem, as empresas atraem mão de obra menos qualificada, geralmente autônoma, para fazer parte de um grupo que acredita estar diante do sonho do empreendedorismo e da autogerência do tempo e dos recursos financeiros. No entanto, apesar dos aparentes benefícios prometidos, tais empresas não conferem ao prestador de serviços qualquer segurança jurídica em relação às suas atividades.

Nesse cenário de precariedade agravado pela pandemia da COVID-19, pode-se depreender do estudo que as mulheres estão em desvantagem, enfrentando salários mais baixos, péssimas condições de trabalho, e dupla jornada que contempla o trabalho remunerado e não remunerado.

A questão da uberização do trabalho ainda aparece ora como embaraço, ora como solução para o problema da omissão por parte do Estado diante aqueles grupos que estão cada vez mais vulneráveis e sensíveis à pobreza, agravada pela desigualdade de renda existente no Brasil. País este em que a discriminação de gênero no mercado de trabalho assevera essa problemática, tendo em vista que discrimina mulheres que muitas vezes são chefes de família e principal fonte de renda nos lares brasileiros.

Deste modo, é necessário enfrentar a situação esposada como uma questão social séria, sendo imprescindível a união de esforços envolvendo diversos atores da sociedade: governos, instituições privadas, academia e a própria população, em busca de mais igualdade e equidade no mercado de trabalho, oportunizando às mulheres a ocupação de espaços livres de preconceito e de inseguranças.

Laborare. Ano IV, Número 7, Jul-Dez/2021, pp. 30-47. ISSN 2595-847X. https://revistalaborare.org/ DOl: https://doi.org/10.33637/2595-847x.2021-91 


\section{REFERÊNCIAS BIBLIOGRÁFICAS}

ABILIO, Ludmiila Costheck. Uberização do trabalho: A subsunção real da viração. Site Passapalavra/ Blog da Boitempo. Disponível em: $<$ https://blogdaboitempo.com.br/2017/02/22/uberizacao-do-trabalho-subsuncao-realda-viracao>. Acesso em 22 mar 2021.

Uberização: A era do nanaempreendedor de si? Anais do $43^{\circ}$. Encontro da ANPOCS. Caxambu, Brasil: Anpocs, 2019.

Sem maquiagem - o trabalho de um milhão de revendedoras de cosméticos. Editora Boitempo, 2013. subordinado.
$<$ https://www.psicoperspectivas.cl/index.php/psicoperspectivas/article/viewFile/

Uberização: Do empreendedorismo para o autogerenciamento 1674/1079>. Acesso em 22 mar 2021.

ARAÚJO, Ângela Maria Carneiro; LOMBARDI, Maria Rosa. Trabalho Informal, Gênero e Raça no Brasil do Início do Século XXI. v. 43. n.149. p. 452-477. Cadernos de Pesquisa, 2013.

BAYLÃO, André Luís da Silva; SCHETTINO, Elisa Mara Oliveira. A inserção da mulher no mercado de trabalho brasileiro. XI Simpósio de Excelência em Gestão e Tecnologia, 2014.

BBC BRASIL. Com pandemia entregadores de app têm mais trabalho, menos renda e maior risco à saúde. Disponível em: $<$ https://www.bbc.com/portuguese/brasil-53258465>. Acesso em: 27 mar 2021.

BERNARDO, J. Democracia totalitária: Teoria e prática da empresa soberana. São Paulo, Brasil: Cortez, 2004.

BIAVASCHI, Magda Barros et al. A terceirização no contexto da reconfiguração do capitalismo contemporâneo: a dinâmica da construção da Súmula no 331 do TST. Revista do Tribunal Superior do Trabalho, v. 80, p. 19-35, 2014.

BRASIL. Constituição da República Federativa do Brasil. Brasília, 1988. Disponível em: <http://www.planalto.gov.br/ccivil 03/constituicao/constituicao.htm> Acesso em 30 de mar de 2021.

Decreto-Lei $\mathbf{n}^{0}$ 5.452, de $\mathbf{1}^{\circ}$ de maio de 1943. Rio de Janeiro, 1943. Disponível em: <http://www.planalto.gov.br/ccivil_03/decreto-lei/del5452.htm> Acesso em 15 de mar de 2021.

Laborare. Ano IV, Número 7, Jul-Dez/2021, pp. 30-47. ISSN 2595-847X. https://revistalaborare.org/ DOI: https://doi.org/10.33637/2595-847x.2021-91 
. Lei $n^{0}$ 11.340, de 7 de agosto de 2006. Brasília, 2006. Disponível $\mathrm{m}$ $<$ http://www.planalto.gov.br/ccivil_03/_Ato2004-2006/2006/Lei/L11340.htm> Acesso em 10 de mar de 2021.

CAPETTI, Pedro. Mais de $\mathbf{7 0 0}$ mil empresas que fecharam as portas não vão reabrir após fim da pandemia. Disponível em O Globo de 16 de julho de 2020: $<$ https://oglobo.globo.com/economia/mais-de-700-mil-empresas-que-fecharam-asportas-nao-vao-reabrir-apos-fim-da-pandemia-24535458>. Acesso em 27 mar 2021.

CARDOSO, Adalberto; PERES, Thiago Brandão. A "modernização das relações de trabalho", a informalidade e a pandemia. Disponível em: $<$ https://www.eco.unicamp.br/remir/index.php/blog/227-a-modernizacao-dasrelacoes-de-trabalho-a-informalidade-e-a-pandemia>. Acesso em 27 mar 2021.

CASTILHO, Paulo Cesar Baria de. Subordinação por algoritmo nas relações de trabalho.

Disponível em: $<$ https://www.jota.info/opiniao-e-analise/artigos/subordinacao-por-algoritmo-nasrelacoes-de-trabalho-17062019>. Acesso em 27 mar 2021.

CERIONI, Carla. Políticas para proteção de trabalhadores sob demanda devem ser prioridade em 2021. Disponível em: $<$ https://www.jota.info/coberturasespeciais/nova-economia/regulamentacao-relacoes-flexiveis-trabalho-prioridade2021-06112020> . Acesso em 27 mar 2021.

COSTA, Simone da Silva. Pandemia e desemprego no Brasil. Revista de Administração Pública, Rio de Janeiro- RJ, 54 (4): 969-978, jul. ago.2020.

DOLCE, Julia. O lado sombrio do trabalho para aplicativos - e como é pior para mulheres. Exame. Disponível em: <https://exame.com/carreira/o-lado-sombrio-do-trabalho-paraaplicativos-e-como-e-pior-para-mulheres/>. Acesso em: 20/03/2021.

FRANÇA, A. L.; SCHIMANSKI, Édina. Mulher, trabalho e família: uma análise sobre a dupla jornada feminina e seus reflexos no âmbito familiar. Emancipação, ISSN-e, 1982-7814, vol. 9, n. 1, págs. 65-78, 2009. Disponível em: https://dialnet.unirioja.es/servlet/articulo?codigo=4025711. Acesso em: 19 mar 2021.

GARCIA, Alessandro Barreto. Trabalho feminino em dose dupla: onde está o lazer? Motrivivência Ano XXI, $\mathrm{n}^{\mathrm{o}} 32 / 33$, p. 375-388, 2010. Disponível em: https://periodicos.ufsc.br/index.php/motrivivencia/article/download/21758042.2009n32-33p375/14142/47978>. Acesso em: 27 mar 2021.

INSTITUTO BRASILEIRO DE GEOGRAFIA E ESTATÍSTICA (IBGE). Pesquisa Nacional por Amostra de Domicílios. Rio de Janeiro: IBGE; 2015.

Laborare. Ano IV, Número 7, Jul-Dez/2021, pp. 30-47. ISSN 2595-847X. https://revistalaborare.org/ DOI: https://doi.org/10.33637/2595-847x.2021-91 
INSTITUTO DE PESQUISA ECONÔMICA APLICADA (IPEA). Trabalho para o mercado e trabalho para casa: persistentes desigualdades de gênero. Brasília: Ipea, 2019. Disponível em: https://www.ipea.gov.br/portal/index.php? option=com_content\&view=article\&id=35255\&Itemid=9. Acesso em: 15 mar 2021.

JOBIM, Tissiano da Rocha. A Lei Maria da Penha e Reflexos no Direito do Trabalho. Disponível em: < http://www.granadeiro.adv.br/boletim-abr07/N6030407.php>. Acesso em:13 mar 2021.

KLEIN, N. Sem logo: A tirania das marcas em um planeta vendido. São Paulo, Brasil: Record. (2002).

LEITE, Carlos Henrique Bezerra. Curso de Direito do Trabalho. 12. ed. São Paulo: Saraiva Educação, 2020.

MACHADO, Leandro. Dormir na rua e pedalar 12 horas por Dia: A rotina dos entregadores por aplicativo. BBC News Brasil. Disponível em: $<$ https://www.bbc.com/portuguese/brasil-48304340\#: :text=V

\%C3\%ADdeos-,Dormir\%20na\%20rua\%20e\%20pedalar\%2012\%20horas\%20por

$\% 20$ dia,rotina $\% 20$ dos $\% 20$ entregadores $\% 20 \mathrm{de} \% 20$ aplicativos\&text $=\mathrm{Um} \% 20$ deles

$\% 20$ explica\%3A\%20\%22Dou\%20entrevista,para\%20voc\%C3\%AA\%2C\%20sim

$\% 2 \mathrm{C} \% 20$ par\%C3\%A7a.\&text $=\mathrm{O} \% 20$ grande $\% 20$ rel $\%$ C3\%B3gio $\% 20$ no

\%20Conjunto,de\%20entrega\%20em\%20S\%C3\%A3o\%20Paulo>. 2019.

MARTINS, Sergio Pinto. Direito do Trabalho. 28 ed. São Paulo: Atlas, 2012.

MOREIRA, A.; HERMANSON. M. De ambulante a motorista de aplicativo: Brasil tem 39 milhões no trabalho informal. Disponível em: $<$ https://www.brasildefato.com.br/2019/05/03/de-ambulante-a-motorista-deaplicativo-brasil-tem-39-milhoes-no-trabalho-informal>. Acesso em: 22 mar 2021.

ONU MULHERES, Brasil. Princípios de empoderamento das mulheres. 2016.

OST, Stelamaris. Mulher e mercado de trabalho. Âmbito Jurídico, 2009. Disponível em: <https://ambitojuridico.com.br/edicoes/revista-64/mulher-e-mercadode-trabalho/\#: : text=A\%20introdu\%C3\%A7\%C3\%A3o\%20da\%20mulher\%20no,do $\% 20$ sistema\%20capitalista\%2C\%20no\%20s\%C3\%A9c>. Acesso em: 13 mar. 2021.

PERET, Eduardo. Mulher estuda mais, trabalha mais e ganha menos do que o homem. AgÊncia IBGE Notícias. Disponível em: <https://agenciadenoticias.ibge.gov.br/agencianoticias/2012-agencia-de-noticias/noticias/20234-mulher-estuda-mais-trabalha-maise-ganha-menos-do-que-o-homem>. Acesso em: 20/03/2021.

Laborare. Ano IV, Número 7, Jul-Dez/2021, pp. 30-47. ISSN 2595-847X. https://revistalaborare.org/ DOI: https://doi.org/10.33637/2595-847x.2021-91 
SCHOLZ, Trebor. Cooperativismo de plataforma: contestando a economia do compartilhamento corporativa. São Paulo: Fundação Rosa Luxemburgo; Editora Elefante, Autonomia Literária, 2016.

SOUZA, Mariluce Karla Bomfim. Medidas de distanciamento social e demandas para reorganização dos serviços hemoterápicos no contexto da Covid-19. Disponível em: <https://scielosp.org/pdf/csc/2020.v25n12/4969-4978/pt> . Acesso em 27 mar 2021.

SOUZA, Sérgio Ricardo de. Comentários à Lei de Combate à Violência Contra a Mulher. 3 ed. Curitiba: Juruá, 2009.

STANDING, Guy. Até a pornografia tem: o que é uberização, como surgiu e outras dúvidas. Uol. Disponível em: $<$ https://tab.uol.com.br/faq/uberizacao-o-que-ecomo-funciona-como-surgiu-e-outras-duvidas.htm>. Acesso em: 20/03/2021.

TEIXEIRA, Cíntia Maria. As mulheres no mundo do trabalho: Ação das mulheres, no setor fabril, para ocupação e democratização dos espaços público e privado. Psic.: Teor e Pesq., Brasília, Abr-Jun 2009, Vol. 25 n.2, pp. 237-244.

UBER. O compromisso da Uber com as brasileiras. Uber. Disponível em: $<$ https://www.uber.com/pt-BR/newsroom/o-compromisso-da-uber-com-asbrasileiras/>. Acesso em: 20/03/2021.

Recebido: $14 / 04 / 2021$

Revisado: 04/05/2021

Aprovado: 19/05/2021

Laborare. Ano IV, Número 7, Jul-Dez/2021, pp. 30-47. ISSN 2595-847X. https://revistalaborare.org/ DOI: https://doi.org/10.33637/2595-847x.2021-91 